\title{
Numerical Simulation of Projectile Impact on Mild Steel Armour Plates using LS-DYNA: Part I: Validation
}

\author{
A. Deb ${ }^{1}$, M. Raguraman ${ }^{1}$, N.K. Gupta 2 , and V. Madhu ${ }^{3}$ \\ ${ }^{I}$ Indian Institute of Science, Bangalore-560 012 \\ ${ }^{2}$ Indian Institute of Technology Delhi, New Delhi-110 016 \\ ${ }^{3}$ Defence Metallurgical Research Laboratory, Hyderabad-500 258
}

\begin{abstract}
The paper describes the simulation of impact of jacketed projectiles on steel armour plates using explicit finite element analysis as implemented in LS-DYNA. Validation of numerical modelling includes a comprehensive mesh convergence study leading to insights not previously reported in literature, using shell, solid, and axisymmetric elements for representing target plates. It is shown for a number of cases that with a proper choice of contact algorithm, element size, and strain rate-dependent material properties, computed projectile residual velocities can match closely with corresponding test-based values. The modelling requirements are arrived at by correlating against published test residual velocities ${ }^{1}$ for variants of mild steel plates (designated as MS1, MS2 and MS3) of different thicknesses at impact velocities in the range of $\sim 820-870 \mathrm{~m} / \mathrm{s}$. Using the validated numerical procedure, a number of parametric studies such as the effect of projectile shape and geometric aspect ratios as well as plate thickness on residual velocity have been carried out and presented in Part II of the current paper.
\end{abstract}

Keywords: Projectile, mild steel plate, ballistic impact, simulation, LS-DYNA

\section{INTRODUCTION}

The behaviour of armour plates subjected to impact by projectiles for velocities including and exceeding ballistic limits, has been investigated primarily using the following approaches: (a) controlled experimentation ${ }^{1-6}$, (b) estimation of residual velocity and ballistic limit with the aid of semi-empirical and limit-state solutions s, $^{2,8}$, and (c) finite element-based contact-impact analysis ${ }^{9-19}$. The third approach, if properly validated, could be considered as the most potent approach for predicting ballistic limits of armour plates and for designing optimised as well as innovative solutions.

In the current study, with an objective of arriving at a robust finite element modelling procedure, a comprehensive convergence study, not previously reported in the published literature, was carried out wrt element size. Shell, solid, and axisymmetric elements were considered and the applicability of shell elements, limited by plate thickness, in predicting experimentally determined residual velocity was ascertained. Solid elements representing target plates are shown to be reliable for both thin and moderately thick plates. The convergence of projectile residual velocity using Belytschko-Lin-Tsay (BLT) shell and constant stress solid elements representing mild steel plates of different hardness is studied by correlating the experimental results reported by Gupta \& Madhu ${ }^{1}$. In the material constitutive model, the effect of strain rate on yield stress and failure 
strain was considered; however, thermal effects were not accounted for. For the impact velocities considered here, which are well in the ordnance range, the computed results are not expected to be substantially influenced by this latter assumption as observed by Backman and Goldsmith ${ }^{4}$. It may be noted that all analyses were carried out with the explicit contact-impact analysis code LS-DYNA. A user-friendly surface-to-surface contact with erosion option in LS-DYNA was chosen for shell and solid elements and 2-D automatic interface algorithm for axisymmetric elements. Having established confidence in the modelling procedures that could yield converged residual velocity for single-layered plates, a number of studies were carried out by varying plate thickness, projectile parameters, impact velocity, etc., which are presented in the Part II of this paper. The modelling guidelines developed here can thus be useful in efficiently creating new design solutions which can otherwise consume considerable time and resources if attempted through physical testing.

\section{FINITE ELEMENT MODELLING OF TARGET PLATE AND PROJECTILE}

Finite element models of a given target plate using shell, solid, and axisymmetric elements are shown in Figs 1, 2, and 3, respectively. For analysis using LS-DYNA, BLT shell elements based on a co-rotational formulation and constant stress solid elements were chosen. To start with, these models were employed for studying the effects of mesh size on convergence of computed projectile residual velocity wrt test values given by Gupta \& Madhu ${ }^{1}$. The plate was square in shape with dimensions of $200 \mathrm{~mm} \times 200 \mathrm{~mm}$ and was clamped at the four corners. Plates of three different thicknesses, viz,. $4.7 \mathrm{~mm}, 6 \mathrm{~mm}$ and $10 \mathrm{~mm}$ were considered. The jacketed ogival-nosed projectile targeting the plate centre was modelled with solid elements as shown in Fig. 4. The projectile core had a dia of $6.2 \mathrm{~mm}$, was $28 \mathrm{~mm}$ long and weighed $5.2 \mathrm{~g}$. It was made of a hard steel alloy with an approximate hardness of $900 \mathrm{VPN}$. The core was enclosed in a copper sheath which increased the total dia of the shot to $7.8 \mathrm{~mm}$.

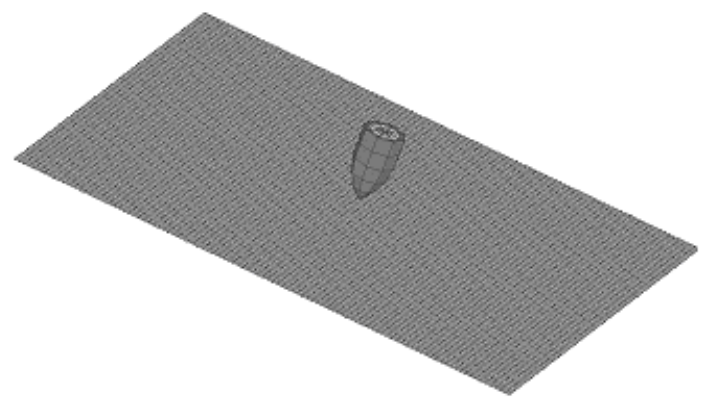

Figure 1. Plate modelled with shell elements and projectile with solid element.

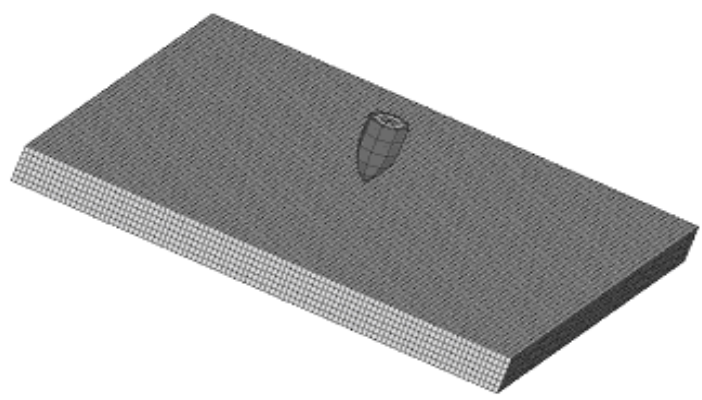

Figure 2. Plate and projectile modelled with solid elements.

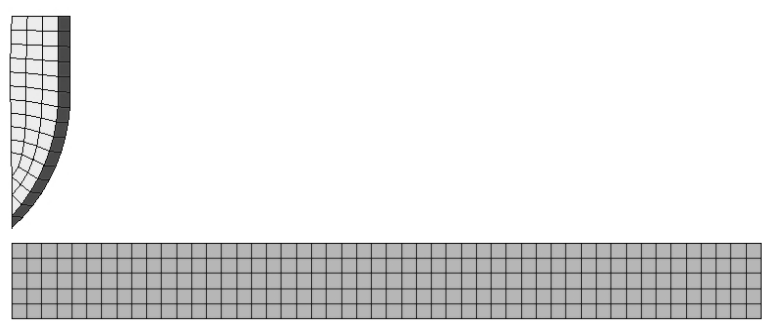

Figure 3. Plate and projectile modelled with axisymmetric elements.

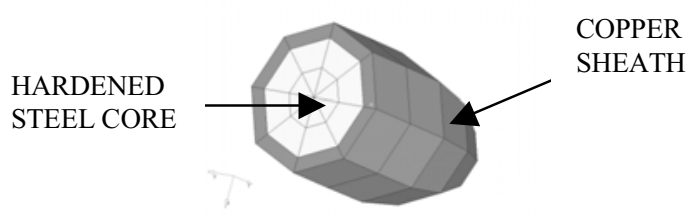

Figure 4. Close-up view of jacketed projectile modelled with solid elements in Figs 1 and 2. 


\subsection{Strain Rate-based Material Modelling of Target Plate}

The material model with the keyword *MAT_STRAIN_RATE_DEPENDENT_PLASTICITY (material type 19) in LS-DYNA was used for defining the behaviours of three variants of MS (mild steel) plates designated as MS1, MS2 and MS3 by Gupta \& Madhu ${ }^{1}$. In this constitutive model, yield and tensile strengths can be specified in a tabular manner wrt strain rate. The quasi-static engineering properties of these steel plates for the hardness ranges quoted by Gupta \& Madhu ${ }^{1}$ are listed in Table 1.

Table 1. Quasi-static engineering properties of mild steel plates

\begin{tabular}{ccccc}
\hline $\begin{array}{c}\text { Plate } \\
\text { material } \\
\text { nomen- } \\
\text { clature }^{1}\end{array}$ & $\begin{array}{c}\text { Vickers } \\
\text { hardness }_{\text {range }} \\
\text { VPN }\end{array}$ & $\begin{array}{c}\text { Quasi- } \\
\text { static } \\
\text { yield } \\
\text { strength } \\
\text { (MPa) }\end{array}$ & $\begin{array}{c}\text { Quasi- } \\
\text { static } \\
\text { tensile } \\
\text { strength } \\
\text { (MPa) }\end{array}$ & $\begin{array}{c}\text { Quasi- } \\
\text { static } \\
\text { elongation } \\
\text { at break } \\
(\%)\end{array}$ \\
\hline MS1 & $110-115$ & 205 & 380 & 25 \\
MS2 & $150-155$ & 360 & 505 & 35 \\
MS3 & $140-145$ & 305 & 465 & 34 \\
\hline
\end{tabular}

The quasi-static engineering stresses were at first converted to corresponding true values using a standard procedure based on a constant volume assumption during a uniaxial tensile test. True instantaneous strain was interpreted as the logarithm of instant gage length divided by its original value.

From the variations of yield and tensile strengths wrt to strain rate for three varieties of steel designated as DP800, HSLA350 and HSS590 by Brenda ${ }^{20}$, it was noticed that the rate of increase of the respective strengths was nearly the same for all the steel grades mentioned. Hence, similar variations of yield and failure strengths with reference to strain rate could be adopted for the present mild steel variants (i.e., MS1, MS2, and MS3) of target plates. The following scaling relation enables defining the dynamic yield and failure strengths of mild steel plates considered here:

$$
\sigma_{\dot{\varepsilon}}^{\text {(steel type })}=\sigma_{\dot{\varepsilon}_{0}}^{(\text {steel type })} \cdot \frac{\sigma_{\dot{\varepsilon}}^{(H S S 590)}}{\sigma_{\dot{\varepsilon}_{0}}^{(H S S 590)}}
$$

where, $\sigma_{\dot{\varepsilon}}^{\text {(steel type) }}$ is the strength (yield or failure) at a given strain rate, $\dot{\varepsilon}\left(\mathrm{s}^{-1}\right)$; and $\sigma_{\dot{\varepsilon}_{0}}^{\text {(steel type) }}$ is the corresponding quasi-static strength at a low strain rate of $\dot{\varepsilon}_{0}\left(\mathrm{~s}^{-1}\right)$. A regression-based curve fitting approach was used to obtain the yield and failure strengths of a target material by extrapolation at a high strain rate (e.g., $10,000 \mathrm{~s}^{-1}$ ) not considered ${ }^{20}$. The approach outlined leads to a set of idealised true stress versus true strain curves as shown in Fig. 5 for various strain rates for each mild steel plate variant being studied here.

It may be noted that the methodology employed here for obtaining strain rate effect on material strength by scaling as per Eqn (1) has been found to be useful in other applications also such as lowvelocity impact on a grade of mild steel plate ${ }^{21}$ distinct from MS1, MS2, and MS3, and ballistic impact on aluminium plates ${ }^{22}$. In the latter case, the reference material was a grade of aluminium (and not HSS 590 considered in Eqn (1)) for which published data on strain rate sensitivity was available. Implicit in the current approach is the assumption that the material for which strain rate-based strength is being derived behaves in a similar manner as the reference material in terms of rate of increase of strength (yield or ultimate) wrt strain rate.

\subsection{Material Modelling of Jacketed Projectile}

The projectile core has been assumed as rigid based on the physical observation that only sheath erosion occurred in the tests carried out in Eqn (1) against which comparisons have been made here. The sheath is modelled with material type 24 in LS-DYNA designated with the keyword *MAT_PIECEWISE_LINEAR_PLASTICITY using the nominal engineering properties of copper listed in Table 2. It may be noted that strain rate sensitivity has not been considered in the material modelling of the projectile.

\section{ELEMENT SIZE ON PROJECTILE RESIDUAL VELOCITY}

The objective of this study was to determine an optimal element size on plate surface as well 


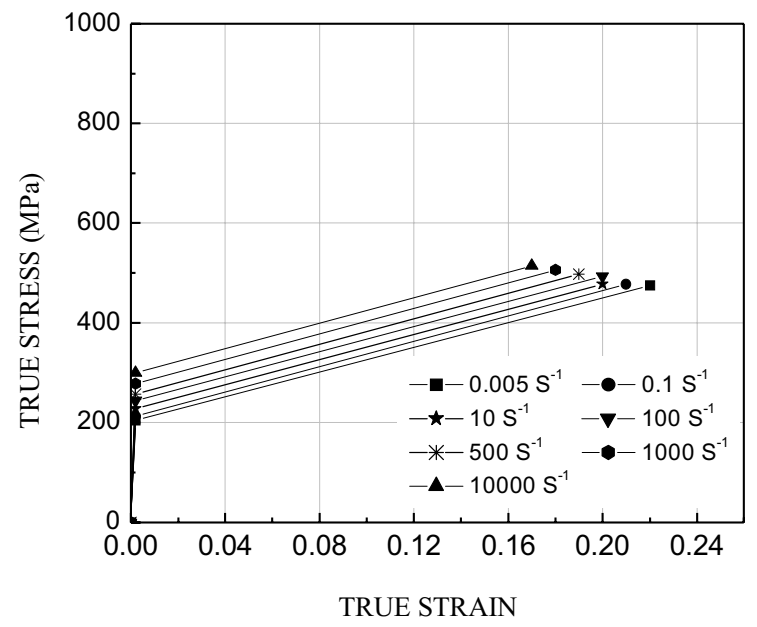

(a)

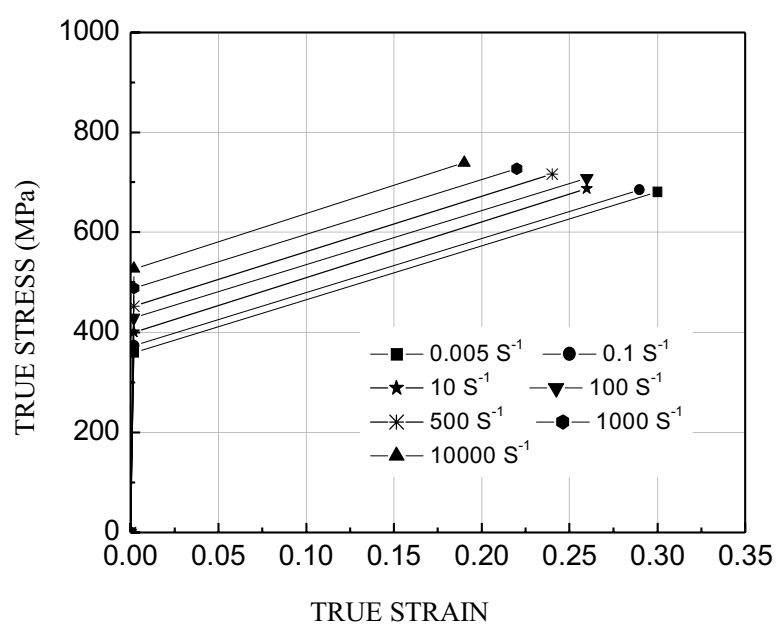

(b)

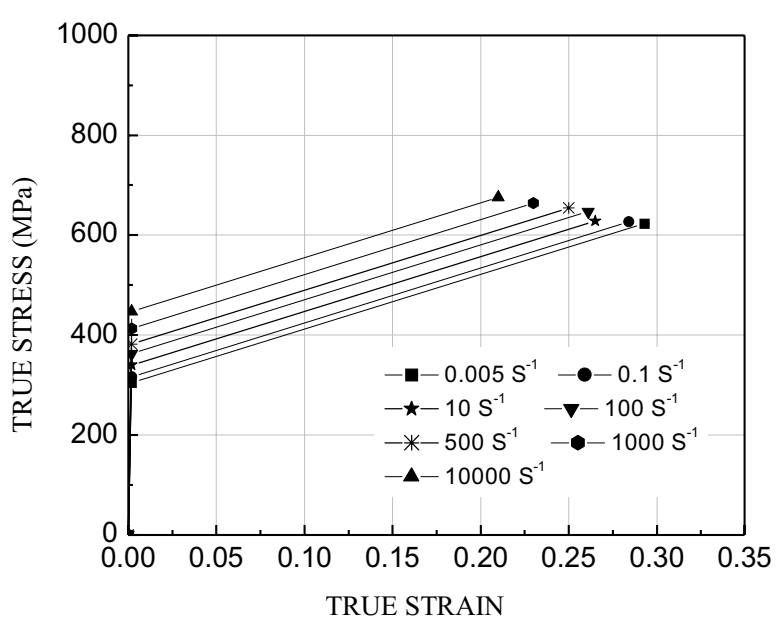

(c)

Figure 5. True stress versus true strain behaviours of (a) MS1, (b) MS2, and (c) MS3 plates.
Table 2. Projectile properties used in simulation

\begin{tabular}{lccccc}
\hline $\begin{array}{l}\text { Projectile } \\
\text { component }\end{array}$ & $\begin{array}{c}\text { Elastic } \\
\text { modulus } \\
\text { (GPa) }\end{array}$ & $\begin{array}{c}\text { Poisson's } \\
\text { ratio }\end{array}$ & $\begin{array}{c}\text { Yield } \\
\text { strength } \\
\text { (MPa) }\end{array}$ & $\begin{array}{c}\text { Tensile } \\
\text { strength } \\
\text { (MPa) }\end{array}$ & $\begin{array}{c}\text { Elongation } \\
\text { at break } \\
\text { (\%) }\end{array}$ \\
\hline $\begin{array}{l}\text { Copper sheath } \\
\begin{array}{l}\text { Hardened } \\
\text { steel inner } \\
\text { core }\end{array}\end{array}$ & 130 & 0.3 & 395 & 405 & 21 \\
\hline
\end{tabular}

as through its thickness (for solid and axisymmetric elements) which will yield reliable values of projectile residual velocity. Plates of varying depths were considered and the computed residual velocities were compared (as in Fig.6 through Fig.8 with the corresponding measured values reported by Gupta \&Madhu ${ }^{1}$. It is seen in Figs 6(a), 7(a) and 8(a) that residual velocity tends to converge monotonically as shell element size decreases, with stiffer meshes (with coarser elements) resulting in lower residual velocities as compared to recorded residual velocities in tests. *CONTACT_ERODING_SURFACE_SURFACE (CESS) interface in LS-DYNA is chosen for analysis. Coefficients of static and dynamic frictions were respectively assigned values of 0.2 and 0.1 as is a common practice. It may be concluded from this study that shell elements of size $1.0-.5 \mathrm{~mm}$ may be used for simulating impact on mild steel target plates of aspect ratio (span/thickness) 20-40.

The convergence characteristics of projectile residual velocity for plates modelled with solid elements are given in Figs 6(b), 7(b), and 8(b). In these cases, the effect of solid element thickness on residual velocity was included in addition to element size on plate surface. It is seen from these figures that good convergence patterns are obtained for all the cases considered. In general, solid elements of size $2 \mathrm{~mm}$ on plate surface yield residual velocities in good agreement with corresponding test values for the plates considered. The desirable thickness of solid elements is $1 / 6^{\text {th }}$ of plate thickness.

Axisymmetric element-based analysis results are shown in Figs 6(c), 7(c), and 8(c) and good convergence characteristics are noted in all cases. Axisymmetric elements of size $2 \mathrm{~mm}$ on plate surface yield residual velocities in good agreement with corresponding test values for all plates analysed. 


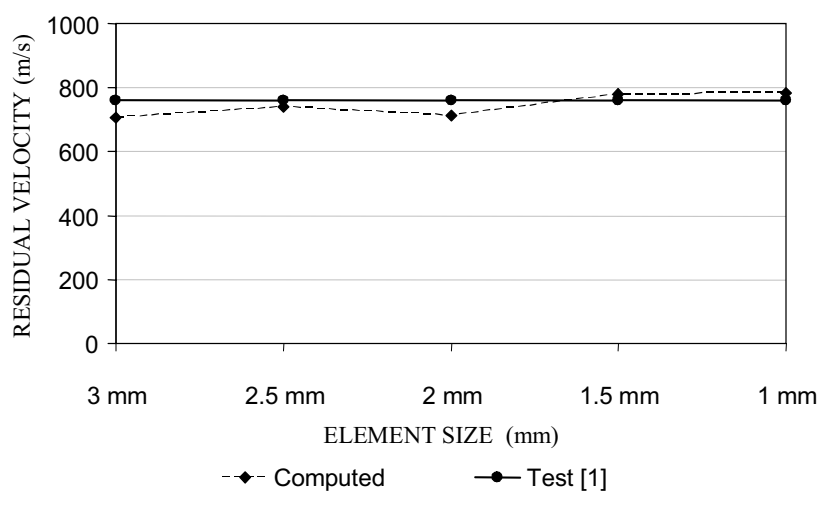

(a)

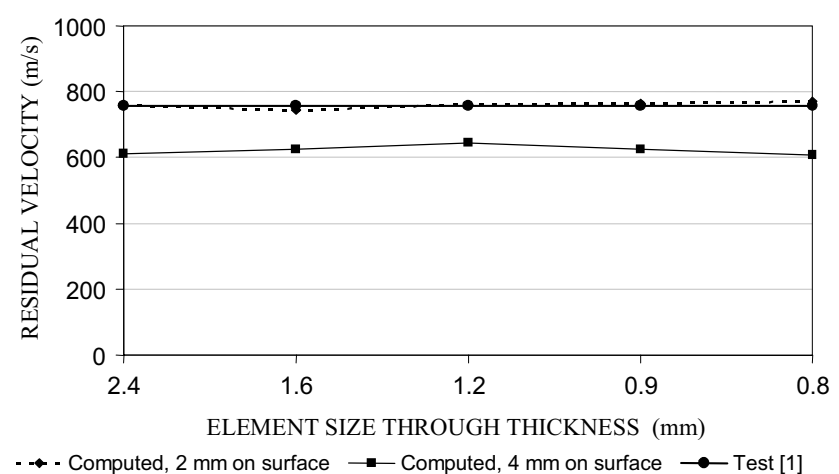

(b)

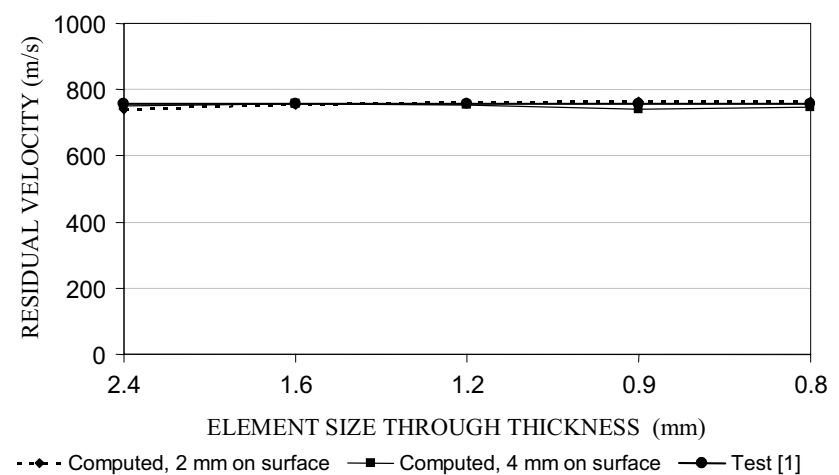

(c)

Figure 6. Projectile velocities for impact on $4.7 \mathrm{~mm}$ thick MS1 plate modelled using: (a) shell elements; (b) solid elements; and (c) axisymmetric elements (impact velocity: $821 \mathrm{~m} / \mathrm{s}$ ).

The desirable thickness of axisymmetric elements is $1 / 6^{\text {th }}$ of plate thickness.

The results hitherto obtained through shell, solid, and axisymmetric element-based analysis using LS-DYNA are compared in Table 3. To assess the degree of correlation of simulation-based residual velocities with test residual velocities, the following

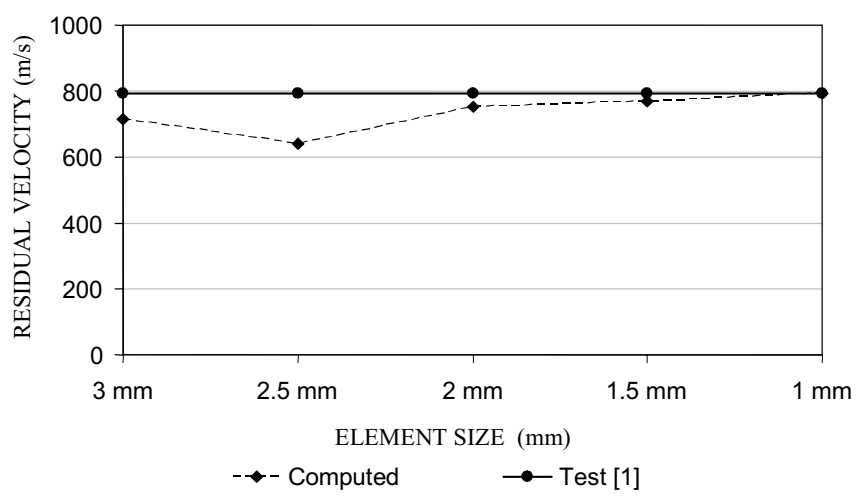

(a)

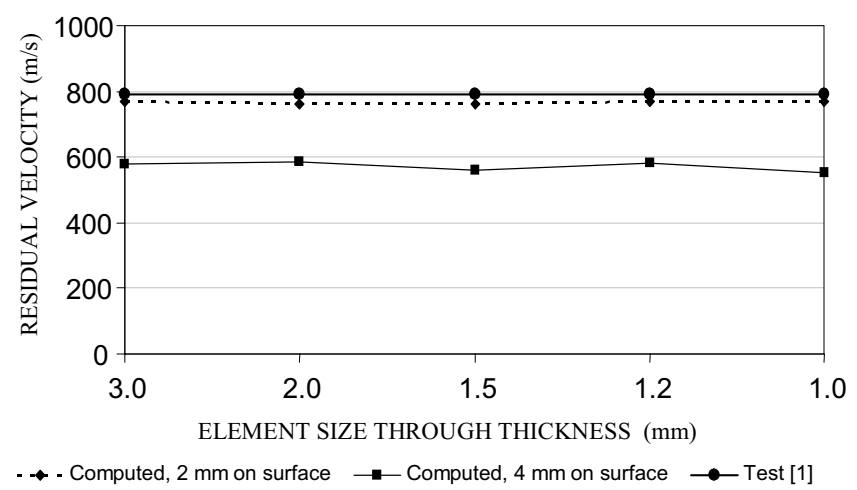

(b)

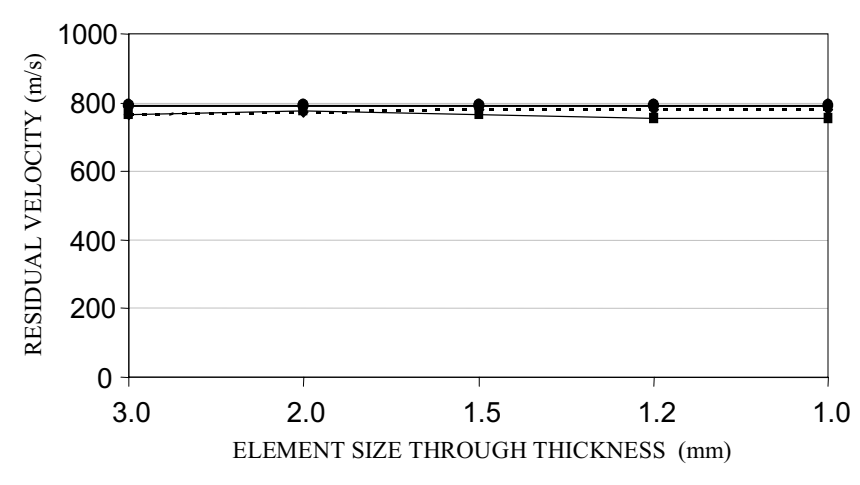

- - Computed, $2 \mathrm{~mm}$ on surface $\rightarrow$ Computed, $4 \mathrm{~mm}$ on surface $\rightarrow$ Test [1]

(c)

Figure 7. Projectile velocities for impact on $6.0 \mathrm{~mm}$ thick MS2 plate modelled using : (a) shell elements; (b) solid elements; and (c) axisymmetric elements (impact velocity: $866.3 \mathrm{~m} / \mathrm{s}$ ).

Correlation Index $(C I)$, is defined:

$$
C I=1-\left\{\frac{\sum e_{i}^{2}}{\sum V_{r}^{2}}\right\}^{\frac{1}{2}}
$$

where $V_{r}$ is the test residual velocity, $e_{i}$ is the difference between the computed and the test residual 


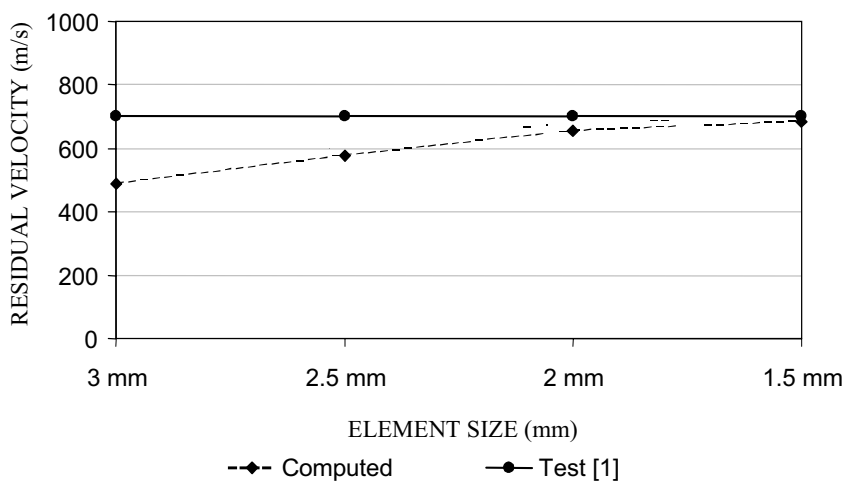

(a)

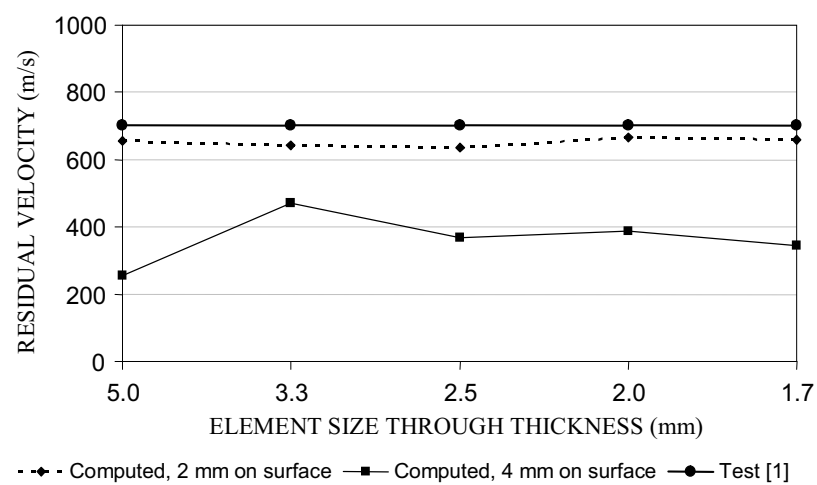

(b)

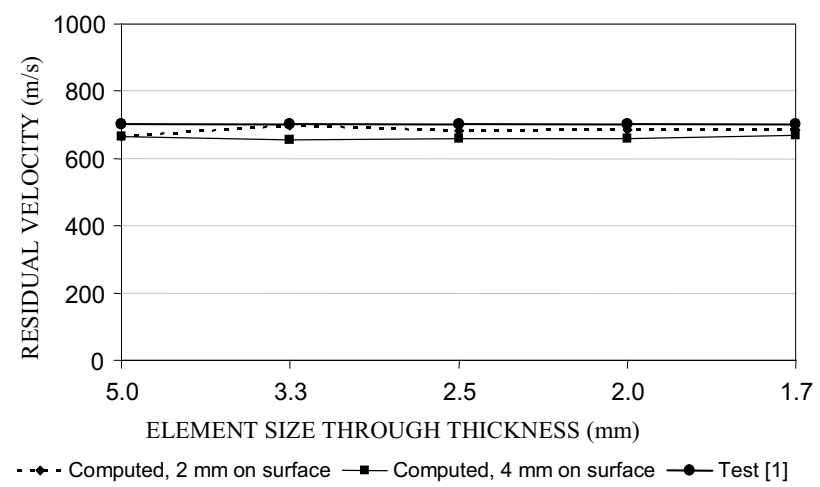

(c)

Figure 8. Projectile velocities for impact on $\mathbf{1 0 . 0} \mathrm{mm}$ thick MS3 plate modelled using: (a) shell elements; (b) solid elements; and (c) axisymmetric elements (impact velocity: $827.5 \mathrm{~m} / \mathrm{s}$ ). velocities, and the summation is carried out over the number of cases for which a combined index of correlation is sought. It is apparent from Eqn (2) that as the degree of correlation increases (i.e., $e_{i}$ decreases), $C I$ approaches unity. For each modelling approach described above, a $C I$ value is calculated by considering all three cases of target plates for which residual velocity convergence study has been carried out. These values of $C I$ are listed in Table 4. It can be inferred from this Table that all element types considered for plate modelling yield extremely good estimation of test residual velocities, although the axisymmetric element-based representation of plate and projectile yields the highest degree of correlation.

It is to be noted that the modelling criteria arrived at above are based on analyses for impact speeds in the range $\sim 820-870 \mathrm{~m} / \mathrm{s}$. However, the ballistic limits for the mild steel target plates analysed are likely to be much lower than this range of impact velocity. For the present modelling procedures to be used with confidence for plate ballistic limit prediction, the convergence of residual velocity has been studied for two lower impact velocities, i.e., $250 \mathrm{~m} / \mathrm{s}$ and $500 \mathrm{~m} / \mathrm{s}$ for MS1 plate of $4.7 \mathrm{~mm}$ thickness. The study revealed similar patterns of convergence as what has been observed at a projectile impact speed of $821 \mathrm{~m} / \mathrm{s}$.

\section{EFFECT OF CONTACT ALGORITHM ON RESIDUAL VELOCITY}

LS-DYNA offers a wide choice of contact interfaces for analysis. A powerful and user-friendly algorithm suitable for most problems, is defined by the keyword *CONTACT_AUTOMATIC_ GENERAL (CAG). For the present category of problems, which involve removal of elements on reaching a failure stress or strain, a common practice

Table 3. Comparison of shell, solid, and axisymmetric element-based prediction of residual velocity

\begin{tabular}{|c|c|c|c|c|c|}
\hline $\begin{array}{c}\text { Plate } \\
\text { thickness } \\
(\mathrm{mm})\end{array}$ & $\begin{array}{c}\text { Projectile } \\
\text { impact velocity } \\
(\mathbf{m} / \mathbf{s})\end{array}$ & \multicolumn{4}{|c|}{ Projectile residual velocity $(\mathrm{m} / \mathrm{s})$} \\
\hline 6.0 & 866.3 & 792.2 & 768.82 & 770.12 & 778.80 \\
\hline 10.0 & 827.5 & 702.2 & 685.93 & 660.17 & 685.18 \\
\hline
\end{tabular}


Table 4. Correlation indices for different types of modelling

\begin{tabular}{lc}
\hline Finite element modelling type & Correlation index \\
\hline Solid element-based & 0.963 \\
Shell element-based & 0.972 \\
Axisymmetric element-based & 0.983
\end{tabular}

is to use an erosion-based contact such as given by the keyword *CONTACT_ERODING_SURFACE_ SURFACE (CESS) already considered in the convergence studies of the previous section. Here, results from CAG and CESS options are compared to establish objectively that CESS is indeed a better choice. In the present comparative study of CAG and CESS interfaces, BLT shell element-based representation of target plate is used. It is seen in Fig. 9 that residual velocity converges faster to corresponding test residual velocity when CESS interface is used. In addition, it has been observed occasionally that although residual velocity matches well with the test value for CAG-based simulation, a complete perforation in target plate is not visible. On the other hand, CESS-based simulations at impact velocities higher than ballistic limits always lead to a clear visual perforation of target plate.

It has been seen from Figs 6 to 8 that test residual velocities represent an upper bound for the numerically computed residual velocities for all modelling approaches considered here. It is further seen in Fig. 9 that CESS condition consistently leads to a faster convergence of residual velocity for plates of various thicknesses. Although the study in Fig. 9 is limited to shell element-based discretisation of target plate, a similar behaviour has been observed for solid element-based target modelling.

Based on the above observations, it can be concluded that the CESS option should be preferred over the CAG condition for ballistic impact simulation with LS-DYNA.

\section{SIMULATION-BASED FAILURE PATTERNS OF TARGET PLATE}

In the previous sections, the ability of the present numerical procedure for predicting residual

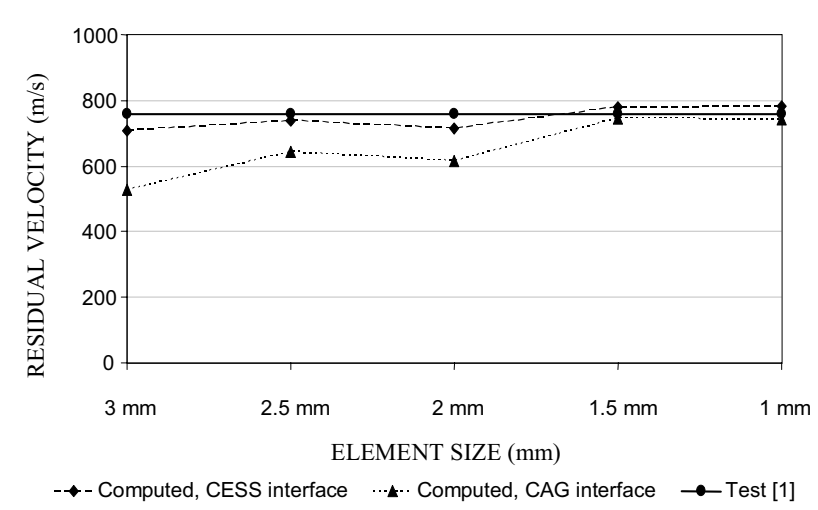

(a) $4.7 \mathrm{~mm}$ thick MS1 plate

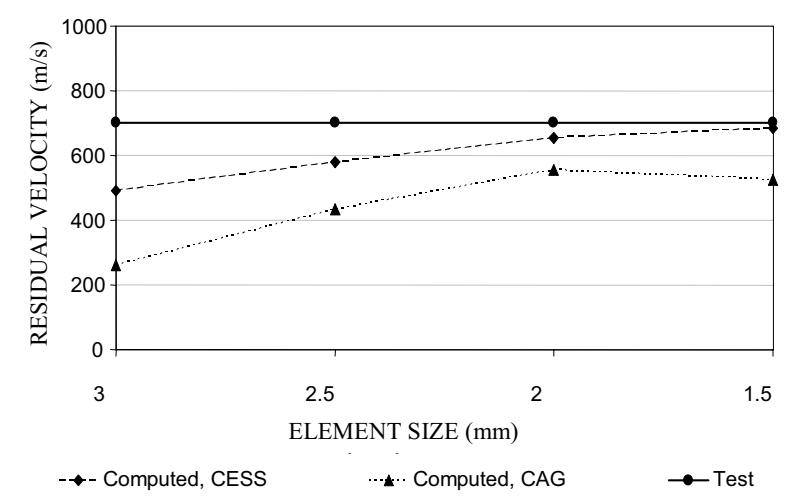

(b) $6 \mathrm{~mm}$ thick MS2 plate

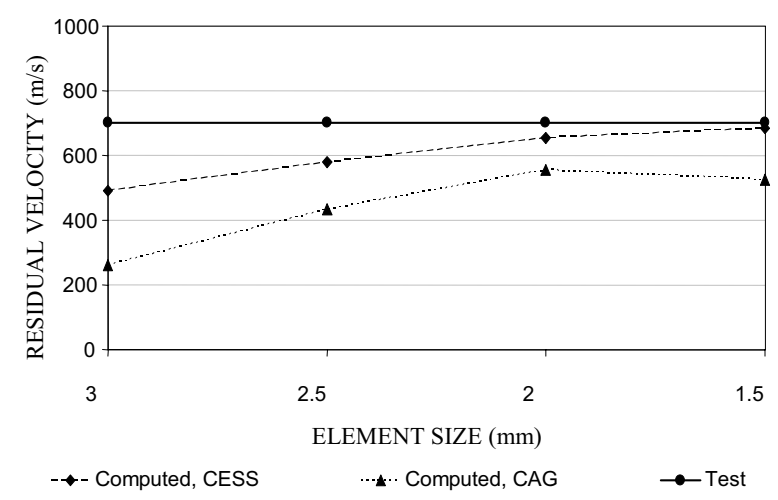

(c) $10 \mathrm{~mm}$ thick MS3 target plate

Figure 9. Effect of contact algorithm on residual velocity.

velocity has been established. Snaps-shots of penetration and perforation of MS1 plates obtained through analysis are shown in Fig.10. This figure shows that the copper sheath of projectile is partially eroded during target plate perforation although the erosion is higher for target plate modelled with solid elements. For plates of higher thickness (corresponding to MS2 and MS3 varieties), the 
DEB, et al:: NUMERICAL SIMULATION OF PROJECTILE IMPACT ON MILD STEEL ARMOUR PLATES

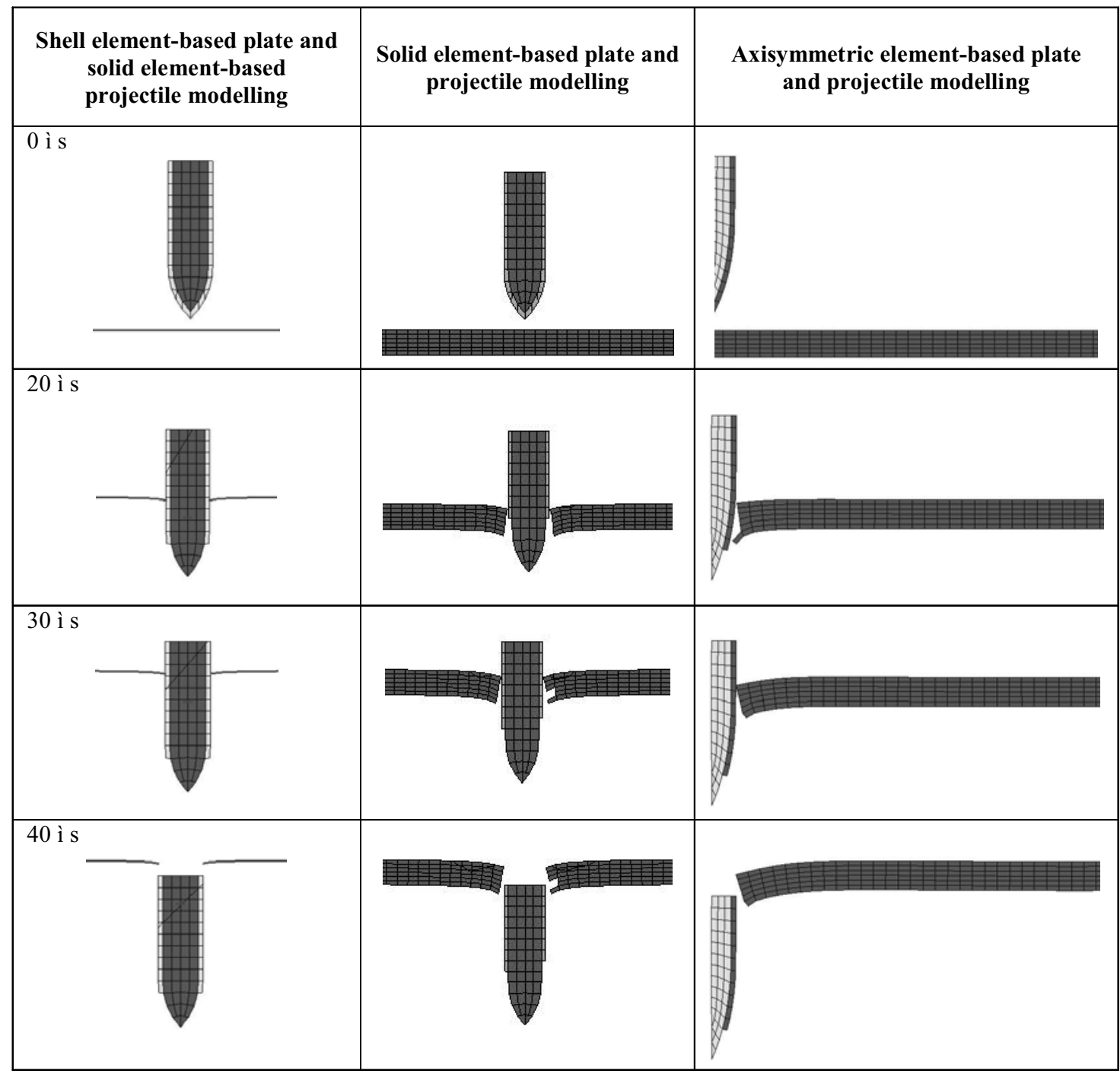

Figure 10. Snap-shots of failure modes of $4.7 \mathrm{~mm}$ thick MS1 target plate.

erosion of projectile copper sheath increases substantially. Such partial-to-significant erosion of projectile sheath has been observed in actual tests. The presence of localised bulging of perforated target plate with minimal dishing (i.e.,plate bending) in shell-, solid-, and axisymmetric-based modelling of target plate as seen in Fig. 10 has been reported in tests at velocities substantially higher than ballistic limit (as is the scenario here).

\section{CONCLUSIONS}

The present paper details a comprehensive finite element-based study of ballistic impact on moderately thick mild steel plates of different grades with a low-calibre jacketed projectile. The mesh convergence study reported here has led to objective guidelines for simulation of mild steel target plates subject to ballistic impact. A comparison of three different modelling techniques has been done for the first time which removes a degree of confusion that may have existed in published literature on preference for any of these approaches. A consistent and easy-to-grasp procedure has been outlined for material modelling of mild steel plates by capturing strain rate effects. The ability of the current modelling techniques in predicting residual velocity and plate failure mode indirectly confirms earlier observations of experts that thermal effects are not significant for velocities not exceeding the ordnance range. The present convergence study also establishes 
the advantages of CESS algorithm over the popular CAG algorithm used for crash analysis in LSDYNA; furthermore, it has been shown that the modelling criteria obtained here for velocities in the range $\sim 820-870 \mathrm{~m} / \mathrm{s}$ are also valid at a substantially lower velocity of $250 \mathrm{~m} / \mathrm{s}$. The modelling procedures developed here can thus be applied with confidence for carrying out numerical parametric studies for armour plate design.

\section{ACKNOWLEDGEMENTS}

The authors are thankful to the Secretary, Armament Research \& Development Board (AR\&DB), DRDO, Government of India for sponsoring the work reported in this paper. The authors are also grateful to Mr M.D. Upadhyay, AR\&DB New Delhi, for his interest, advice, and encouragement that greatly aided the successful completion of the present work.

\section{REFERENCES}

1. Gupta, N.K. \& Madhu, V. An experimental study of normal and oblique impact of hardcore projectile on single and layered plates. Int. J. Impact Engg., 1992, 19, 395-14.

2. Gupta, N.K.; Ansari, R. \& Gupta, S.K. Normal impact of ogival nosed projectiles on thin plates. Int. J. Impact Engg., 2001, 25, 641-60.

3. Corran, R.S.J.; Shadbolt, P.J. \& Ruiz, C. Impact loading of plates - An Experimental investigation. Int. J. Impact Engg., 1983, 1(1), 3-22.

4. Backman, M.E. \& Goldsmith, W. The mechanics of penetration of projectile into targets. Int. J. Engg. Sci., 1978, 16, 1-99.

5. Tan, V.B.C.; Lim, C.T. \& Cheong, C.H. Perforation of high strength fabric by projectiles of different geometry. Int. J. Impact Engg., 2003, 28, 207-22.

6. Borvik, T., et al. Perforation of $12 \mathrm{~mm}$ thick steel plates by $20 \mathrm{~mm}$ diameter projectiles with flat, hemispherical and conical noses: Part I: Experimental study. Int. J. Impact Engg., 2002, 27, 19-35.
7. Jones, N. Structural impact. Cambridge University Press, 1989.

8. Corbett, G.G.; Reid, S.R. \& Johnson, W. Impact loading of plates and shells by free-flying projectiles: a review. Int. J. Impact Engg., 1996, 18, 141230 .

9. Kad, B.K.; Schoenfeld, S.E. \& Burkins, M.S. Through thickness dynamic impact response in textured Ti-6Al-4V plates. Mater. Sci. Engg. A, 2002, 241-51.

10. Tabiei, A. \& Ivanov, I. Computational micromechanical model of flexible woven fabric for finite element impact simulation. Int. J. Numerical Meth. Engg., 2002, 1259-276.

11. Lim, C.T.; Shim, V.P.W. \& Ng, Y.H. Finiteelement modelling of the ballistic impact of fabric armour. Int. J. Impact Engg., 2003, 28, 13-31.

12. Nandlall, D.; Williams, K. \& Vaziri, R. Numerical simulation of the ballistic response of GRP plates. Composites Sci. Tech., 1998, 1463-469.

13. Bessette, G.C., et al. Modelling of impact problems using an h-adaptive explicit lagrangian finite element method in three dimensions. Comput. Meth. Appl. Mech. Engg., 2003, 1649-679.

14. Espinosa, H.D., et al. A numerical investigation of penetration in multilayered material/ structure systems. Int. J. Solids Struct., 1998, 2975-3001.

15. Hassan, M., et al. Investigation of high velocity impact on integral armour using finite element method. Int. J. Impact Engg., 2000, 203-17.

16. Park, M.; Yoo, J. \& Chung, D-T. An optimisation of multi-layered plate under ballistic impact. Int. J. Solids Struct., 2005, 123-37.

17. Fawaz, Z.; Zheng, W. \& Behdinan, K. Numerical simulation of normal and oblique ballistic impact on ceramic composite armours. Composite Structures, 2004, 63, 387-95. 
18. Borvik, T., et al. Perforation of $12 \mathrm{~mm}$ thick steel plates by $20 \mathrm{~mm}$ diameter projectiles with flat, hemispherical and conical noses: Part II: Numerical study. Int. J. Impact Engg., 2002, 27, 37-64.

19. Martineau, R.L.; Prime, M.B. \& Duffey, T. Penetration of HSLA-100 steel with tungsten carbide spheres at striking velocities between 0.8 and $2.5 \mathrm{~km} / \mathrm{s}$. Int. J. Impact Engg., 2004, 505-20.

20. Benda, Y. Fatigue behaviour of advanced high strength steels for automotive applications. American
Iron and Steel, Ispat Inland Inc., February 2003. http://www.autosteel.org.

21. Deb, A.; Raguraman, M. \& Jones, N. Numerical prediction of low velocity impact phenomena for mild steel plates with blunt strikers. In Proceedings of Symposium on Plasticity and Impact Mechanics (IMPLAST), 2007, pp. 63946.

22. Raguraman, M. \& Deb, A. Robust prediction of residual velocities and ballistic limits of projectiles for impact on thin aluminium plates. In Proceedings of $9^{\text {th }}$ International Conference on Structures Under Shock and Impact (SUSI), 2006, pp. 205-14.

\section{Contributors}
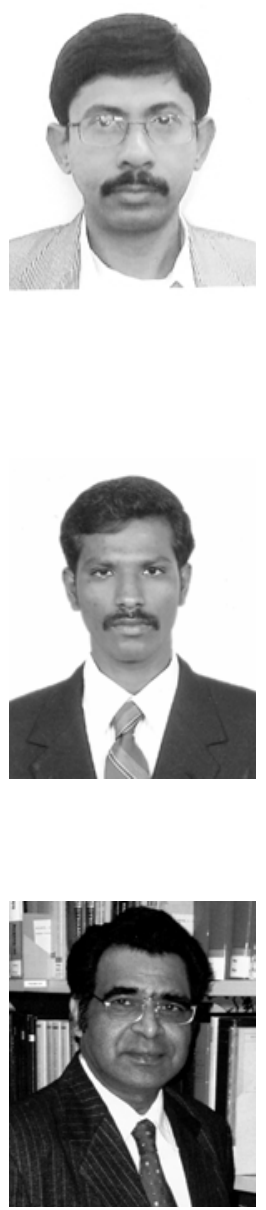

Dr Anindya Deb is presently working as Assoc Prof at the Centre for Product Design and Manufacturing, Indian Institute of Science (IISc), Bangalore. He obtained his PhD from the State University of New York at Buffalo, ME from the Memorial University of Newfoundland, St. John's, Canada, and BE from Jadavpur University, Calcutta. His areas of interest are: CAE in product design, crashworthiness of transportation systems and occupant safety, impact modelling and testing, design of automotive systems, and hybrid methods in design. He has obtained four patents on vehicle head impact safety countermeasures and one Indian design registration on a lightweight car, and has published a number of papers in international journals and conference proceedings.

Mr M. Raguraman received his BE and ME in Production Engineering from the PSG College of Technology, Coimbatore. He has recently completed his PhD from the Centre for Product Design and Manufacturing, IISc, Bangalore in the area of CAE-driven design of metallic armour plates for ballistic impact. Presently, he is working as a researcher at the School of Mechanical Engineering, University of Leeds, UK.

Prof N.K. Gupta is serving as a Henry Ford Chair Emeritus Professor at Indian Institute of Technology (IIT) Delhi, New Delhi, since 2005. He has been with the Department of Applied Mechanics, IIT Delhi, New Delhi, since 1971. He works in the area of large deformations of metals and composites at low, medium and high rates of loading. He has published his researches in national and international journals, guided researches at $\mathrm{PhD}$ and MTech levels, and undertaken national and international research and consultancy projects. He is recipient of Erskine Award (New Zealand), Alexander von Humboldt Research Award (Germany), and several other honours and awards He was conferred Padma Shri in 1991. 


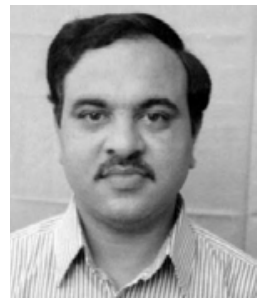

Dr Vemuri Madhu is working as Scientist F at the Armour Development Division, of the Defence Metallurgical Research Laboratory, Hyderabad. He obtained his BE (Civil Engg) in 1984 from NIT, Trichy and PhD (Applied Mech) in 1993 from IIT Delhi. He worked as Post Doctoral Research Fellow at the University of California, Los Angeles, USA, during 1997-98. He has more than 22 years of experience in the field of design, development, and integration of advanced composite armour materials and systems for protective applications. He has been associated with several major defence research projects that have contributed to development of knowledge on protective systems for many military applications. He has more than 25 research publications to his credit. 